\title{
PENERAPAN TEKNOLOGI PRODUKSI DAN KEUANGAN PADA PENGERAJIN BAMBU DI KABUPATEN JEMBER
}

\section{IMPLEMENTATION OF FINANCIAL AND PRODUCTION TECHNOLOGY IN BAMBOO CREAMERS IN JEMBER DISTRICT}

\author{
Sumadi $^{\# 1}$, Didiek Hermanuadi ${ }^{\# 2}$, Rediyanto Putra ${ }^{\# 3}$ \\ ${ }^{\# 1}$ Program Studi Akuntansi Sektor Publik, Politeknik Negeri Jember \\ Jl. Mastrip Kotak Pos 164 Jember \\ \#2 Program Studi Teknologi Produksi Pangan, Politeknik Negeri Jember \\ Jl. Mastrip Kotak Pos 164 Jember \\ \#3urusan Akuntansi, Universitas Negeri Surabaya \\ Jl. Ketintang No. 2 Surabaya \\ ${ }^{1}$ madideha57@gmail.com \\ ${ }^{2}$ didiek.hermanuadiegmail.com \\ ${ }^{3}$ rediputra.rp@gmail.com
}

\begin{abstract}
Abstrak
Program pengabdian ini dilakukan dengan menggunakan skema pengabdian desiminasi Kementrian Riset, Teknologi, dan Pendidikan Tinggi untuk anggaran tahun 2019. Program pengabdian ini dilakukan dengan tujuan untuk meningkatkan efisiensi dan efektivitas kegiatan produksi dan tata kelola keuangan yang ada di KUB Andrika Jaya dan KUB Ida Jaya. Kedua mitra yang ada pada program pengabdian ini merupakan usaha pengerajin bambu yang berasal dari Jember. Metode pengabdian ini dilakukan dengan menggunakan metode survei, perbaikan kualitas bahan baku, dan program pelatihan. Program pengabdian ini telah menghasilkan peningkatan efisiensi dan efektivitas kegiatan produksi yang dihasilkan dari penerapan teknologi mesin produksi yang meliputi yaitu mesin, pengering, mesin sender, dan mesin pemotong bambu. Selain itu, program pengabdian ini juga telah menghasilkan program aplikasi keuangan sederhana berbasis excel dan penerapan aplikasi akuntansi berbasis android. Mitra berharap agar kegiatan pengabdian ini dapat berjalan secara kontinu agar dapat menciptakan keberlanjutan perkembangan pada usaha yang telah dijalankan.
\end{abstract}

Kata Kunci: desiminasi teknologi, teknologi produksi, teknologi keuangan

\section{Abstract}

This dedication program is carried out using the Ministry of Research, Technology and Higher Education desimination service deduction scheme for the 2019 budget. This service program is carried out with the aim of increasing the efficiency and effectiveness of production and financial management activities at the AndUB Jaya KUB and Ida Jaya KUB. The two partners in the service program are bamboo craftsmen from Jember. This service method is carried out using survey methods, improving the quality of raw materials, and training programs. This service program has resulted in increased efficiency and effectiveness of production activities resulting from the application of production machinery technology which includes machines, dryers, senders, and bamboo cutting machines. In addition, this service program has also produced an excel-based simple financial application program and the application of an Android-based accounting application. Mitra hopes that this community service activity can run continuously in order to create sustainable development in the business that has been run.

Keywords : financial technology, production technology,technology dissemination

\section{PENDAHULUAN}

Industri kerajinan bambu telah lama tumbuh dan berkembang di dalam masyarakat Indonesia. Jenis produknya sangat beraneka macam dan banyak diantaranya yang mendapat peminat di luar negeri. Oleh karena itu persyaratan produk ini semakin diperketat dalam kontak-kontak dagang, mulai dari spesifikasi produk, kualitas, standar ukuran sampai dengan batas waktu penyerahan produk. Hampir seluruh produk dari bambu dibentuk oleh anyaman, terutama untuk peralatan rumah tangga dan hiasan.
Sehingga mutu dan daya saing produknya tergantung dari kehalusan dan kerataan iratannya.

Negara Indonesia merupakan negara yang memiliki jumlah tanaman bambu dalam jumlah yang besar. Luas tanaman bamboo Indonesia mencapai 1.414.375 ha, sedangkan untuk Propinsi Jawa Timur sebesar 542.109 ha [1]. Sehingga bambu merupakan solusi terbaik untuk meningkatkan ekspor non migas karena pertumbuhan bambu yang relatif singkat. Hal ini dikarenakan bambu merupakan tanaman yang dapat memberikan nilai tambah dan menghasilkan 
berbagai jenis produk yang berkualitas jika dikelola dengan menggunakan teknologi yang tepat dan benar [2].

Salah satu kelompok pengrajin bambu yang secara konsisten berproduksi di Kabupaten Jember adalah kelompok pengrajin KUB “Andrika Jaya” dan KUB "Ida Jaya" yang berkedudukan di Desa Antirogo - Kecamatan Sumbersari - Jember, yang telah memulai usahanya sejak tahun 1999 yang lalu. Kelompok pengrajin ini memproduksi aneka kerajinan bambu, mulai dari peralatan rumah tangga sederhana seperti keranjang, kap lampu gantung, wadah buah, wadah kue sampai souvenir dengan pesanan khusus khas daerah. Volume produksi yang relatif besar, total aneka produk yang dihasilkan dapat mencapai kurang lebih 8 sampai 10 ribu unit per bulan,. Jangkauan pemasarannya selama ini, sebagian besara untuk memenuhi permintaan lokal/regional Jawa Timur dan sebagian memenuhi permintaan khusus "buyer" untuk diekspor ke luar negeri.

Namun potensi pasar yang sangat besar dan potensi pengusaha belum diimbangi peningkatan kualitas produk dan pengelolaan usaha yang profesional. Masalah produksi yang dihadapi oleh usaha ini antara lain tingkat keawetan produk kerajinan terhadap serangan jamur dan bubuk, kekeringan bahan baku yang belum sempurna (tingkat kelembaban tinggi) dan kualitas desain produk yang stagnan. Beberapa masalah tersebut dapat diterangkan sebagai berikut :

a) Tingkat keawetan produk kerajinan yang rendah menyebabkan produk kurang berkualitas. Produk kerajinan yang berbahan baku bambu sangat rentan mengalami jamur dan bubuk, sehingga mengurangi tingkat keawetan produk. Kondisi ini disebabkan oleh standarisasi kualitas bahan baku yang kurang diperhatikan, selain itu pennganan bahan baku juga tidak dilakukan proses pengawetan. Akibatnya produk kerajinan bambu mudah diserang jamur 'biru" dan bubuk. Bahkan seringkali produk belum sampai dikirim telah terjadi jamuran sehingga mengurangi kualitas produk. Apalagi bila produk tersebut dipasarkan ke mancanegara yang iklim udara berbeda dengan Indonesia maka seringa mendapat komplain atau ditolak.

b) Pengeringan bahan baku tidak dilakukan secara sempurna. Pengeringan bahan baku dilakukan dengan cara menjemur dengan mengandalkan sinar matahari. Akibatnya waktu pengeringan sangat lama dengan hasil tidak optimum. Apabila musim penghujan produksi bisa terhenti karena bahan baku yang belum memenuhi standart kekeringan. Kondisi ini mengakibatkan kualitas produk menurun, khususnya pada musim penghujan dan produk kerajinan mudah diserang jamur 'biru' karena kelembaban yang sangat tinggi. Oleh karena itu dibutuhkan teknologi pengeringan (oven) bambu untuk mempercepat pengeringan dan tidak tergantung sinar matahari. Dengan adanya oven kualitas produk lebih terjamin dan produksi lebih cepat untuk meningkatkan proses produksi.

c) Kualitas desain produk kerajinan stagnan. Pengembangan desain kerajinan sangat terbatas dan tidak berkembang karena minimnya pengetahuan dan kreatifitas pengrajin. Padahal tuntutan pasar menghendaki kreatifitas yang terus berkembang, baik dari segi desain maupun diversifikasi produk. Umumnya produk kerajinan, seratus persen adalah berupa anyaman dari bambu dan tidak ada kombinasi dengan bahan lain. Padahal produk kerajinan dapat dimodifikasi dan dikombinasikan dengan bahan-bahan lain, seperti kayu, logam, mendong, dsb. Untuk itu diperlukan perbaikan inovasi produk dan diversifikasi jenisnya sehingga produk memiliki daya saing yang handal di pasaran.

d) Permasalahan dari aspek produksi adalah sistem menajemen dan pengelolaan usaha dilakukan secara tradisional. Tidak dilakukan suatu perencanaan usaha, pengelolaan proses produksi yang efisien mulai dari penyediaan bahan baku, pengelolaan sumberdaya manusia dalam proses produksi, penggudangan, kemasan dan manajemen keuangan secara profesional. Akibatnya perusahaan tidak mampu mengelola pesanan dalam jumlah besar.

e) Pemasaran produk masih bersifat konvensional, UKM kurang aktif memasarkan produknya, sehingga pertumbuhan usaha mengalami stagnasi.

\section{TARGET DAN LUARAN}

Mengingat kondisi tersebut di atas dan spesifikasi kualitas dan kuantitas akan permintaan produk yang terus meningkat, maka perlu segera dilakukan peningkatan pula dari sisi teknologi prosesing dan sistem manajemen usaha dengan rincian sebagai berikut:

a. Sistem penanganan bahan baku dari aspek baik kuantitas maupun kualitasnya - perlu diperbaiki, salah satunya dengan introduksi mesin pengering bambu.

b. Teknologi prosesing yang sangat dibutuhkan calon mitra yakni sistem atau teknologi peralatan produksinya yang kebanyakan masih manual, sehingga kontinuitas produk terganggu utamanya pada order yang memuncak, meliputi penghalus iratan bambu/sender dan mesin bubut bambu

c. Paket program pelatihan pengembangan desain produk kerajinan, sehingga keberlanjutan usaha tetap terjaga.

d. Paket program tata kelola keuangan sederhana 
Solusi yang telah ditawarkan tersebut diharapkan yang akan dilaksanan, dan jenis luaran luaran yang dapat menghasilkan beberapa luaran. Berikut solusi akan dihasilkan

Tabel 1. Rencana Capaian

\begin{tabular}{|l|l|l|}
\hline No. & \multicolumn{1}{|c|}{ Solusi } & \multicolumn{1}{|c|}{ Jenis Luaran } \\
\hline 1 & Introduksi mesin pengering bambu & $\begin{array}{l}\text { 1 unit pengering bambu mekanis kapasitas } 10 \mathrm{~m}^{3} \\
\text { dengan tungku pemanas }\end{array}$ \\
\hline 2 & $\begin{array}{l}\text { Introduksi penggunaan penghalus iratan } \\
\text { bambu dan mesin bubut bambu }\end{array}$ & $\begin{array}{l}\text { 1 unit penghalus iratan bamboo kapasitas } 500 \\
\text { iratan per jam } \\
1 \text { unit mesin bubut bambu yang digerakkan } \\
\text { oleh electromotor }\end{array}$ \\
\hline 3. & Pelatihan manajemen usaha & $\bullet \quad 1$ paket software akuntansi usaha sederhana \\
\hline
\end{tabular}

\section{METODE PELAKSANAAN}

Pelaksanaan kegiatan ini akan dilakukan dengan melibatkan beberapa pihak yaitu KUB "ANDRIKA JAYA" dan KUB "Ida Jaya" selaku UKM yang bersedia untuk diajak kerjasama. Kedua UKM tersebut merupakan UKM yang melakukan kegiatan menghasilkan kerajinan bambu di Desa Antirogo - Kecamatan Sumbersari - Jember, yang telah memulai usahanya sejak tahun 1999 yang lalu. Kegiatan ini akan dilakukan oleh tiga orang yang telah memiliki kompetensi di bidang nya masingmasing yaitu sebagai berikut.

Tabel 2 Daftar Pelaksana Kegiatan

\begin{tabular}{|l|l|l|l|l|}
\hline No & \multicolumn{1}{|c|}{ Nama } & Jabatan & \multicolumn{1}{|c|}{ Keahlian } & \multicolumn{1}{c|}{ Tugas } \\
\hline 1 & Dr. Sumadi, MM & Ketua & $\begin{array}{l}\text { Manajemen } \\
\text { usaha }\end{array}$ & $\begin{array}{l}\text { - Mengkoordiniir seluruh kegiatan } \\
\text { - Manajemen Usaha industri Kerajinan Bambu } \\
\text { - Membuat laporan, publikasi, dan pertanggung } \\
\text { jawaban kegiatan }\end{array}$ \\
\hline 2 & $\begin{array}{l}\text { Ir. Didiek } \\
\text { Hermanuadi, MT }\end{array}$ & Anggota & $\begin{array}{l}\text { Alat Mesin } \\
\text { Pertanian }\end{array}$ & $\begin{array}{l}\text { Rancang bangun Alat mesin pertanian Kerajinan } \\
\text { Bambu } \\
\text { Membantu ketua membuat laporan, publikasi, } \\
\text { dan pertanggung jawaban kegiatan }\end{array}$ \\
\hline 3 & $\begin{array}{l}\text { Rediyanto Putra, } \\
\text { SE, MSA }\end{array}$ & Anggota & Akuntansi & $\begin{array}{l}\text { Membantu kegiatan pelaksanaan terkait dengan } \\
\text { pembukuan dan akuntansi untuk perusahaan } \\
\text { sederhana }\end{array}$ \\
\hline
\end{tabular}

Pelaksanaan program ini dilakukan dengan beberapa tahapan pelaksanaan mulai dari proses perbaikan kualitas bahan baku sampai dengan proses pemberian pelatihan. Deskripsi program pelaksanaan kegiatan ini adalah sebagai berikut :

a) Perbaikan kualitas bahan baku dengan teknologi proses pengawetan bambu

b) Perbaikan teknologi proses produksi dengan introduksi mesin dan peralatan : unit pengering bambu, mesin gergaji bambu, mesin sender, mesin bubut bambu, dan spray gun untuk teknologi pelapisan kayu. c) Paket pelatihan manajemen usaha yang meliputi: sistem pembukuan usaha, sistem pengendalian produksi, pemasaran dan pengembangan usaha.

Teknologi yang akan digunakan untuk memberikan solusi bagi permasalahan yang dihadapi oleh mitra ini adalah melalui introduksi mesin pengering bambu dan penerapan teknologi berupa penghalus iratan bambu/ sender dan mesin bubut bambu. Gambaran dari ketiga jenis teknologi tersebut adalah sebagai berikut.

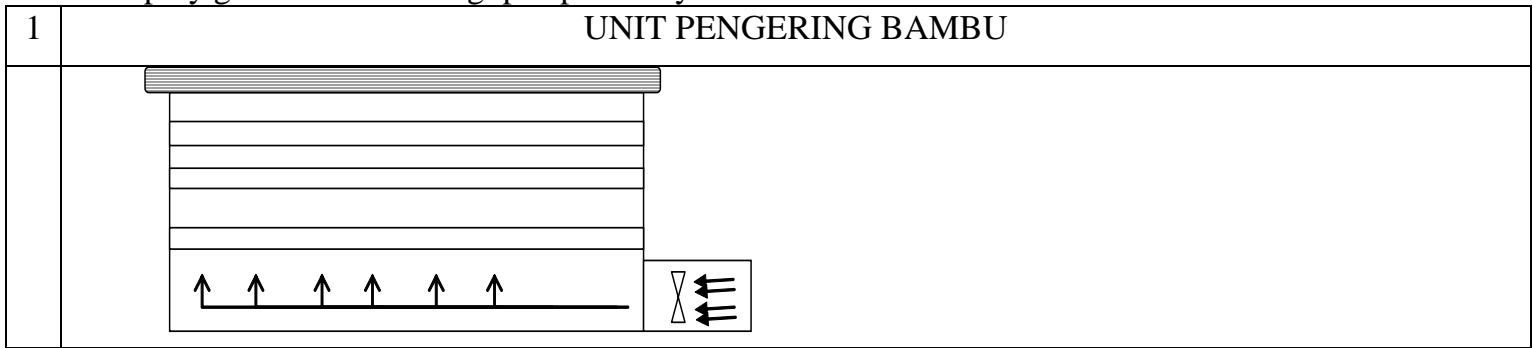




\begin{tabular}{l} 
(a) Fungsi, mengeringkan bambu dan produk sesuai dengan persyaratan mutu, dapat juga digunakan \\
untuk ruang fumigasi (pengawetan) \\
(b) Spesifikasi: Ukuran $3 \mathrm{~m} \times 2,5 \mathrm{~m} \times 3 \mathrm{~m}$, bahhan rangka dari gavalum, dinding dan atap dari fiber, \\
pemanas dari biomasa \\
(c) Keterangan : local design, dilakukan modifikasi sesuai kebutuhan lapang \\
\hline (a) Fungsi, mesin ini berfungsi untuk \\
menghaluskan bumbung bambu sebelum \\
diberi motif \\
(b) Spesifikasi: ukuran utama digerakan oleh \\
motor listrik 3/4 PK, 220V/ 1400 RPM, \\
dengan panjang benda kerja 125 cm, \\
dilengkapi aneka pisau potong dan pisau \\
pembentuk \\
Keterangan: modifikasi pada kepala tetap \\
dan kepala lepas, sehingga memudahkan \\
operasional di lapangan
\end{tabular}

a) Fungsi, mesin ini berfungsi untuk membentuk benda putar simetris

b) Spesifikasi: ukuran utama digerakan oleh motor listrik 3/4 PK, 220V/ 1400 RPM, dengan panjang benda kerja $125 \mathrm{~cm}$, dilengkapi aneka pisau potong dan pisau pembentuk

c) Keterangan: modifikasi pada kepala tetap dan kepala lepas, sehingga memudahkan operasional di lapangan

Penerapan teknologi pada program ini akan digunakan untuk melakukan proses pembuatan kerajinan bambu merupakan gabungan kerja ilmu, teknologi, dan seni yang mempunyai kandungan seni (art) dan fungsional. Mesin dan peralatan yang digunakan untuk dalam pembuatan kerajinan kayu dalam setiap tahapan sebagai berikut :

1) Tahap penyiapan bahan baku kayu umumnya menggunakan gergaji potong kayu manual dan pengeringan dengan sun drying syetem.

2) Tahap pengiratan bambu, tahap ini bertujuan untuk menyiapkan bahan anyaman sesuai keperluan, alat yang digunakan pisau, pahat, dan ampelas kayu. Pada tahap ini juga dilakukan teknik pewarnaan bahan anyaman sesua keperluan.

3) Tahap penganyaman iratan dan pembentukan produk, alat bantu yang digunakan guntung manual.
4) Tahap pengeringan produk, tahap ini dilakukan dengan metoda penjemuran antara 2 sampai 4 hari sesuai dengan persyaratan produk dan kondisi cuaca.

5) Tahap finishing biasanya dilakukan untuk penambahan motif atau aksesoris tambahan lainnya (misalnya untuk produk kap lampu), alat yang digunakan antara lain gungting, mesin jahit, dan kuas untuk pelapisan.

6) Tahap pengepakan untuk keperluan pengiriman.

Kegiatan diseminasi produk teknologi kepada kedua mitra yaitu UKM KUB "ANDRIKA JAYA" dan KUB "Ida Jaya" diharapkan mampu memberikan beberapa dampak yang positif baik dari segi ekonomi dan sosial yaitu sebagai berikut:

\section{A. Dampak Ekonomi Kegiatan}

a) Produk UKM mitra merupakan industri kerajinan yang memberikan nilai tambah, sehingga merupakan 
peluang bisnis untuk pengadaan bahan baku yang diperoleh dari desadesa sekitarnya.

b) Meningkatkan keuntungan atau benefit langsung bagi UKM mitra dengan adanya peningkatan kualitas dan kuantitas produk kerajinan yang dihasilkan

c) Mampu memberikan sumber mata pencaharian masyarakat sekitar UKM mitra. Sehingga diharapkan berkembangnya UKM mitra, maka mampu menjadi salah satu motor penggerak ekonomi wilayah.

d) Mampu memberikan kontribusi terhadap devisa negara dari hasil ekspor produk UKM mitra ke berbagai negara tujuan.

\section{B. Dampak Sosial Kegiatan}

a) Karena mampu menyerap tenaga kerja setempat, sehingga memberikan kontribusi tingkat pengurangan tingkat penggangguran di wilayah pedesaan sekitar UKM mitra.

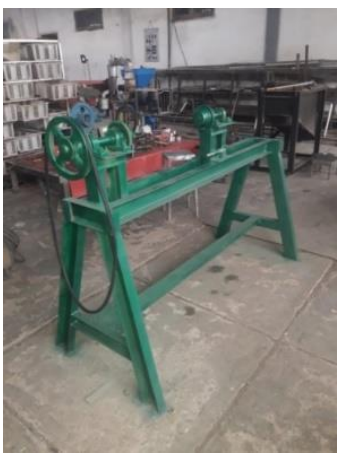

Gambar 1. Mesin Bubut Bambu

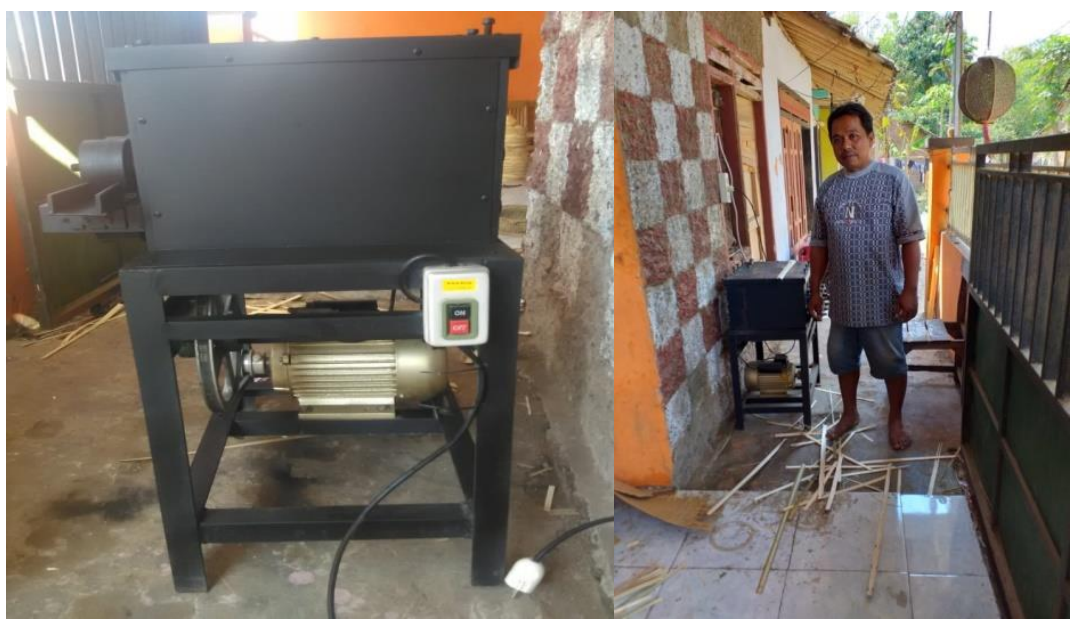

Gambar 2. Mesin Sender

Mesin pengering bambu pada pengabdian desiminiasi ini digunakan untuk mengatasi masalah terkait pengeringan bahan baku tidak dilakukan b) Diharapkan mampu memberikan dampak multiplier effect khususnya menekan tingkat kemiskinan dan kerawanan sosial .

c) Mendorong iklim dan mempercepat lahirnya wirausahawan baru yang mandiri dan profesional. IV. HASIL

\subsection{Pembelian Mesin Produksi}

Kegiatan yang pertama dilakukan pada pengabdian ini adalah pembelian mesin produksi untuk KUB Andrika Jaya dan KUB Idha Jaya. Mesin produksi yang dibeli pada pengabdian desiminasi ini ada 3 jenis yaitu 1 set mesin bubut bambu, 1 set mesin sender, dan 1 set mesin pengering bambu.

Mesin bubut bambu pada pengabdian desiminasi ini digunakan untuk membantu mitra dalam hal menciptakan pemotongan bambu dalam berbagai ukuran secara lebih mudah. Hal ini pada akhirnya akan membuat mitra dapat menghasilkan produk kerajinan dengan ukuran dan ketebalan yang sama untuk setiap produk. Adapun gambar dari mesin bubut bambu yang sudah dibeli pada pengabdian ini adalah sebagai berikut

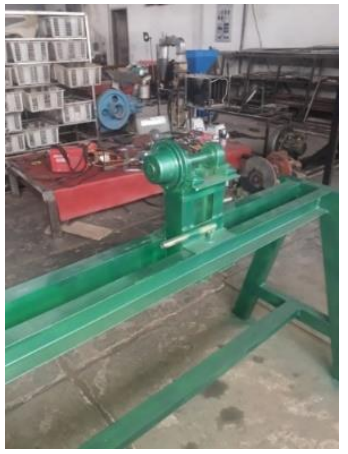

secara sempurna. Selama ini mitra mengeringkan bambu hanya dengan dijemur dan menggunakan bantuan sinar matahari, sehingga proses pengeringan 
menjadi lama dan tidak optimal. Pengeringan yang tidak optimal ini mengakibatkan penurunan kualitas produk kerajinan yang dihasilkan. Oleh karena itu, pada pengabdian ini KUB Andrika Jaya dan KUB
Idha Jaya akan diberi alat pengering bambu untuk mengoptimalkan produksi yang dilakukan. Adapun gambar dari penampakan mesin pengering bambu adalah seperti pada gambar berikut.

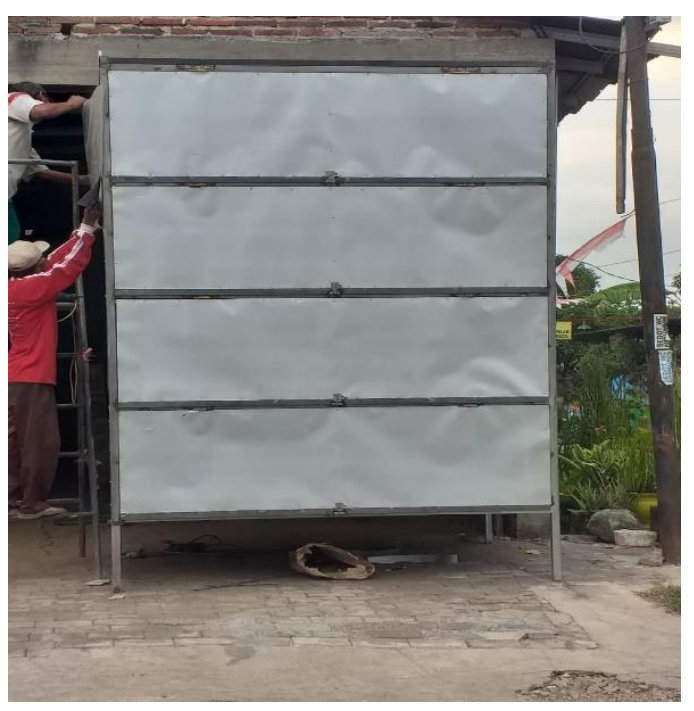

Gambar 3. Mesin Pengering

\subsection{Penerapan Aplikasi Akuntansi Sederhana}

Penerapan aplikasi akuntansi sederhana ini bertujuan untuk menyelesaikan masalah dari KUB Andrika Jaya dan KUB Idha Jaya. Pada paragraf sebelumnya telah dijelaskan bahwa KUB Andrika Jaya dan KUB Idha Jaya memiliki masalah terkait manajemen usaha yang masih tradisional. Masalah ini pada akhirnya berdampak pada pengelolaan keuangan yang ada di KUB Andrika Jaya dan Idha Jaya yang masih tidak teroganisir dengan baik. Oleh karena itu, program pengabdian ini melakukan penerapan aplikasi akuntansi sederhana pada KUB Andrika Jaya dan KUB Idha Jaya untuk memperbaiki tata kelola keuangan yang sudah ada.

Program penerapan aplikasi akuntansi sederhana yang dilakukan pada KUB Andrika Jaya dan KUB Idha Jaya dilakukan dengan menggunakan aplikasi keuangan berbasis android yang ada di
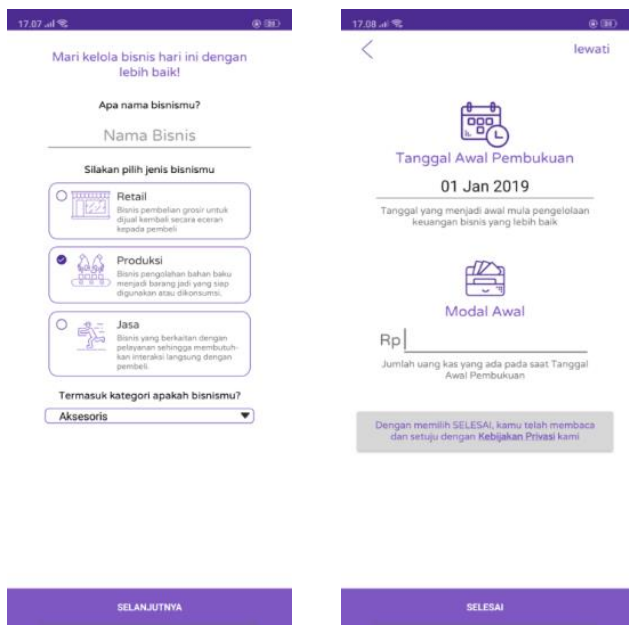

playstore dan aplikasi keuangan berbasis excel yang telah dirancang sebelumnya. Kedua jenis aplikasi keuangan itu diharapkan dapat mempermudah bagi KUB Andrika Jaya dan KUB Idha Jaya dalam melakukan pengelolaan keuangan karena sistemnya yang simpel dan mudah.

Aplikasi keuangan berbasis android dapat digunakan bagi KUB Andrika Jaya dan KUB Idha Jaya untuk melakukan pencatatan transaksi bisnis terkait penjualan usaha. Selanjutnya aplikasi keuangan berbasis excel yang dibuat sendiri dapat digunakan oleh KUB Andrika Jaya dan KUB Idha Jaya untuk mencatat biaya produksi dan membuat laporan biaya produksi. Gambar 3 dan 4 berikut menyajikan mengenai tampilan kedua aplikasi keuangan yang akan diterapkan pada KUB Andrika Jaya dan KUB Idha Jaya.

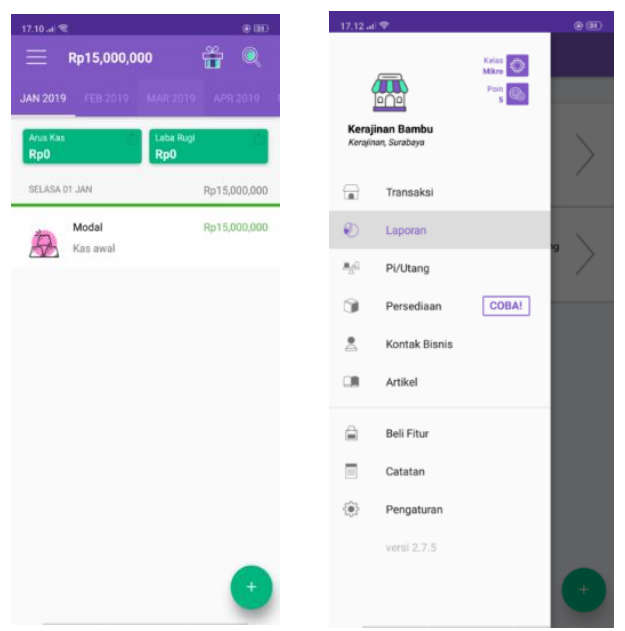



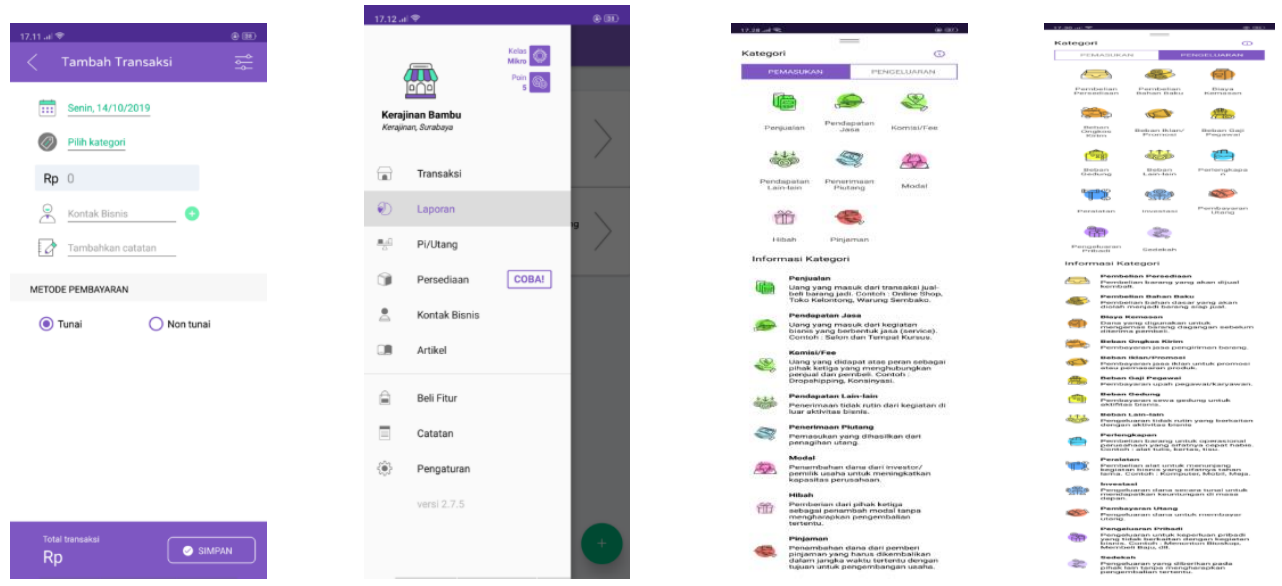

Gambar 3. Aplikasi keuangan berbasis android

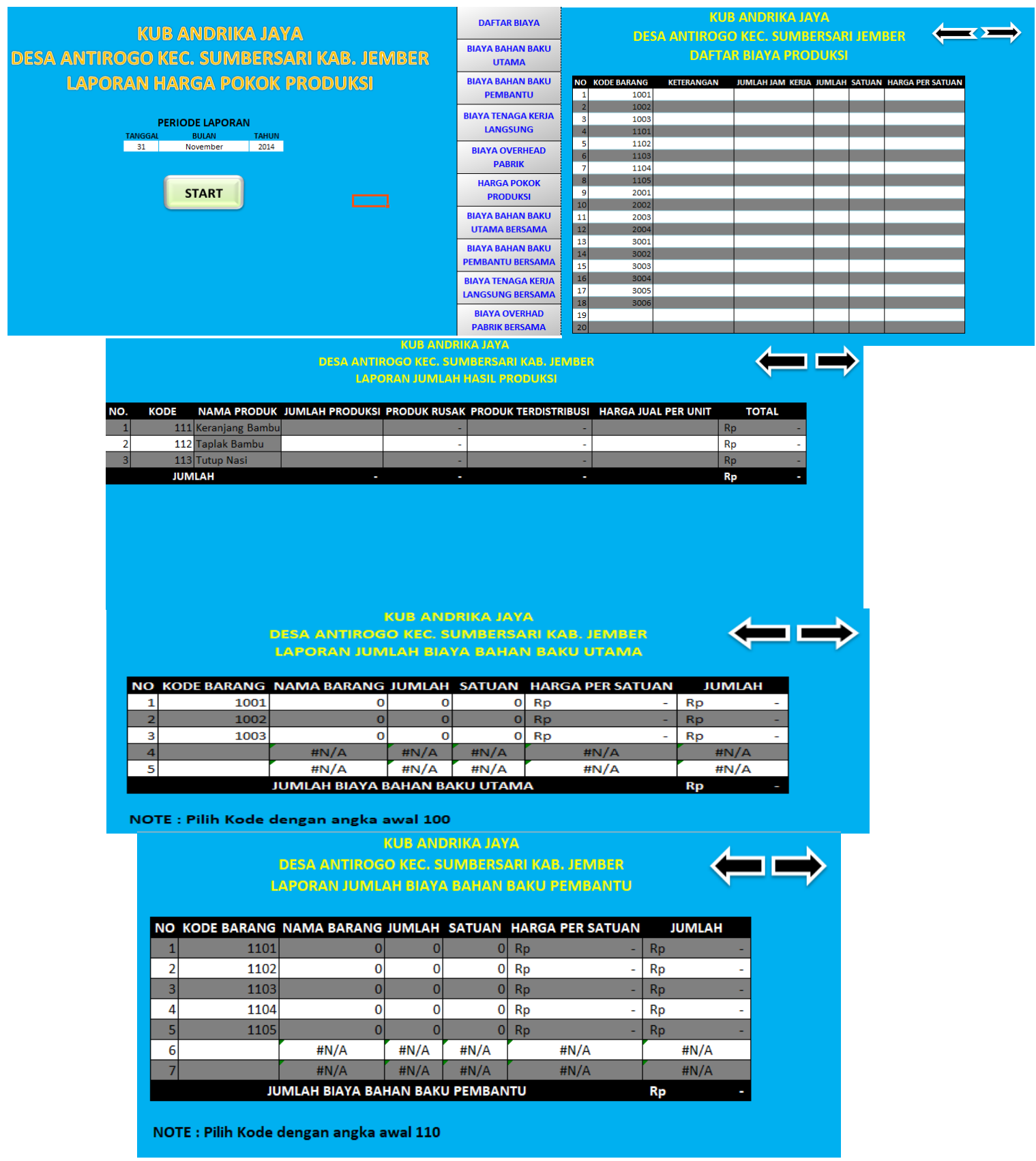




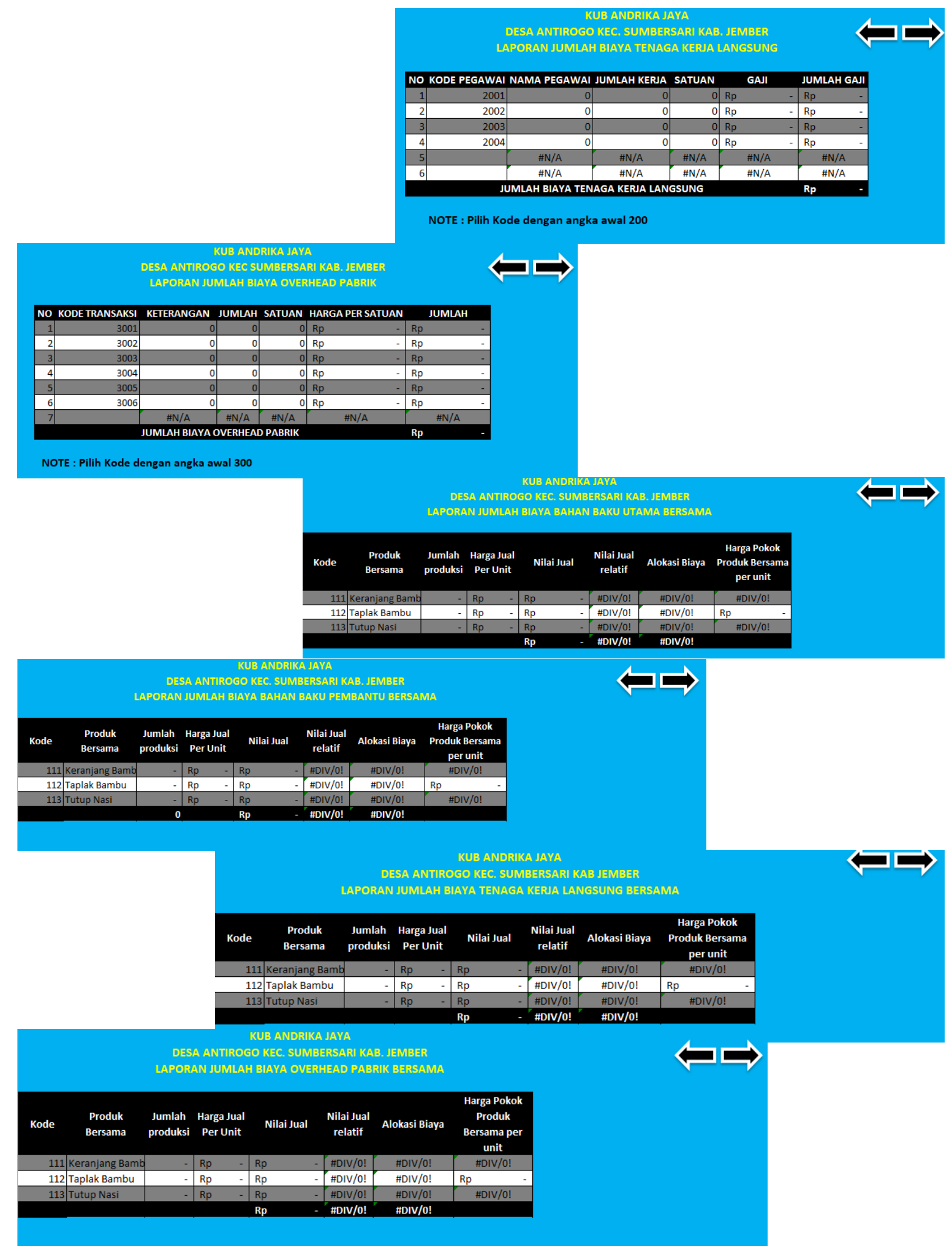




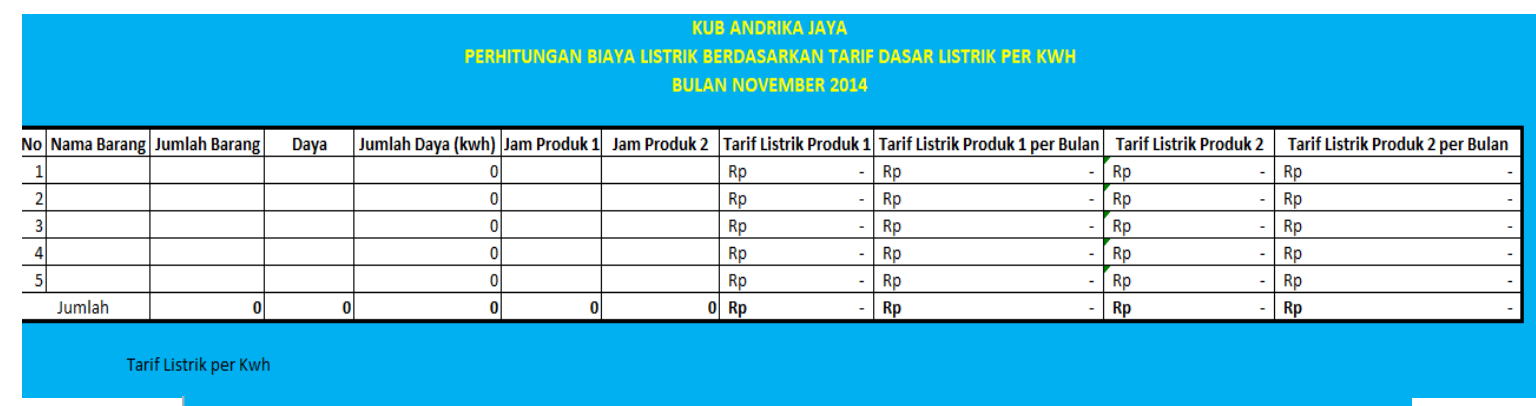

KUB ANDRIKA JAYA

PERHITUNGAN BIAYA BEBAN GEDUNG

BULAN NOVEMBER 2014

\begin{tabular}{|r|l|l|l|lr|}
\hline No. & Nama Produk & Jumlah Tegel & Harga Tegel per satuan & Jumlah Beban Gedung \\
\hline 1 & & & & $\mathrm{Rp}$ & - \\
\hline 2 & & & & $\mathrm{Rp}$ & - \\
\hline 3 & & & & $\mathrm{Rp}$ \\
\hline & & 0 & & \multicolumn{2}{l}{} \\
\hline
\end{tabular}

\section{KESIMPULAN}

Pelaksanaan program pengabdian ini sudah berhasil membuat mitra mengalami perbaikan dalam hal teknologi yang digunakan. Mitra menjadi lebih efektif dan efisien dalam melakukan kegiatan usaha nya dalam bidang produksi dan tata kelola keuangan yang dilakukan. KUB Ida Jaya dan Andrika Jaya berharap kegiatan ini dapat terus berjalan secara kontinu di periode selanjutnya. Tujuan nya agar dapat terjadi keberlanjutan perkembangan yang terjadi pada KUB Andrika Jaya dan KUB Ida Jaya.

\section{UCAPAN TERIMAKASIH}

Ucapan terimakasih tidak lupa disampaikan kepada Kementrian Riset, Teknologi, dan Pendidikan Tinggi yang telah memberikan dukungan dana untuk terlaksananya program pengabdian desiminasi teknologi ini untuk anggaran tahun 2019. Selain itu, penulis juga mengucapkan terimakasih kepada KUB Ida Jaya dan KUB Andrika Jaya yang telah bersedia untuk menjadi mitra pengabdian ini dan bekerjasama untuk kelancaran kegiatan pengabdian desiminasi ini. Ucapan terimakasih juga disampaikan kepada pihak Poluteknik Negeri Jember yang telah membantu dalam hal keperluan administrasi mulai dari proses pengajuan proposal hingga sampai proses akhir pengabdian desiminasi 2019 ini.

\section{DAFTAR PUSTAKA}

[1] Food and Agriculture Organization of The United Nations. 2009. Global Forest Resources Assessment Update 2009 Indonesia Country Report On Bamboo Resources.

[2] Arhamsyah. 2009. Pengelolahan Bambu dan Pemanfaatannya dalam Usaha Pengembangan Industri Kecil Menengah dan Kerajinan 